\title{
Retraction Note to: Coastal atmospheric climate and artificial intelligence English translation based on remote sensing images
}

\author{
Hui Jiang ${ }^{1}$
}

Published online: 11 November 2021

C) Saudi Society for Geosciences 2021

Retraction Note to: Arabian Journal of Geosciences (2021) 14: 475 https://doi.org/10.1007/s12517-021-06713-3

The Editor-in-Chief and the Publisher have retracted this article because the content of this article is nonsensical. The peer review process was not carried out in accordance with the Publisher's peer review policy. The author has not responded to correspondence regarding this retraction.

The original article can be found online at https://doi.org/10.1007/ s12517-021-06713-3.

Hui Jiang

littlegrey@126.com

1 College of Foreign Languages and Literature, Southwest Minzu University, Chengdu 610041, Sichuan, China 